\title{
KORELASI PENGETAHUAN DAN MOTIVASI DENGAN KEAKTIFAN KADER POSYANDU DI WILAYAH KERJA PUSKESMAS WATES KABUPATEN PRINGSEWU LAMPUNG
}

\author{
Cynthia Puspariny \\ Dosen STIKes Muhammadiyah Pringsewu \\ Email: Cynthiabrv85@gmail.com
}

\begin{abstract}
ABSTRAK
Kader merupakan tenaga masyarakat yang dianggap paling dekat dengan masyarakat dan diharapkan mereka dapat melakukan pekerjaannya secara sukarela tanpa menuntut imbalan berupa uang atau materi lainnya. Sekitar $40 \%$ kader masih ada yang kurang aktif dalam kegiatan pelaksanaan posyandu. Tujuan penelitian ini adalah untuk mengetahui korelasi antara pengetahuan dan motivasi dengan keaktifan kader dalam kegiatan posyandu di wilayah kerja Puskesmas Wates Kecamatan Gadingrejo Kabupaten Pringsewu Lampung.

Penelitian ini menggunakan metode deskriptif analitik dengan pendekatan cross sectional. Alat ukur yang digunakan adalah kuesioner. Pada penelitian ini, penentuan sampel menggunakan teknik Cluster Sampling. Sampel yang digunakan adalah 52 responden di wilayah kerja Puskesmas Wates Kecamatan Gadingrejo Kabupaten Pringsewu Lampung. Penelitian ini dilaksanakan pada bulan Mei-Agustus 2016. Uji statistik univariat menampilkan hasil distribusi frekuensi sedangkan bivariat menggunakan Chi Square memperoleh hasil ada hubungan yang signifikan antara tingkat pengetahuan dengan keaktifan kader posyandu di wilayah kerja puskesmas Wates dengan $p$ Value $0,000<0,05$ dan motivasi dengan keaktifan kader posyandu di wilayah kerja puskesmas wates $p$ Value $0,013<0,05$.

Upaya peningkatan pengetahuan dan kesejahteraan kader perlu ditingkatkan lagi guna meningkatkan peran aktif kader posyandu.
\end{abstract}

\section{Kata Kunci : Pengetahuan, Motivasi dan Keaktifan Kader}

\section{PENDAHULUAN}

Posyandu dilaksanakan oleh masyarakat itu sendiri dan merupakan bentuk Upaya Kesehatan Bersumberdaya Masyarakat (UKBM). Tujuan utama posyandu adalah menunjang penurunan Angka Kematian lbu (AKI), Angka Kematian Bayi (AKB) dan Angka Kematian Balita di Indonesia melalui upaya pemberdayaan masyarakat. Posyandu pada prinsipnya adalah lembaga dari, oleh dan untuk masyarakat, dimana pengelolanya dipilih dari masyarakat dan penyelenggaraan kegiatan dilaksanakan oleh kader dan dibantu oleh petugas kesehatan (Depkes RI, 2006).

Kader merupakan tenaga masyarakat yang dianggap paling dekat dengan masyarakat dan diharapkan mereka dapat melakukan pekerjaannya secara sukarela tanpa menuntut imbalan berupa uang atau materi lainnya. Namun ada juga kader kesehatan yang disediakan sebuah 
rumah atau sebuah kamar serta beberapa peralatan secukupnya oleh masyarakat setempat (Meilani, N., dkk, 2008).

Jumlah kader yang bertugas pada hari buka posyandu dapat dijadikan indikasi lancar tidaknya posyandu. Hari buka posyandu merupakan puncak kegiatan posyandu, oleh karena itu banyaknya kader yang bertugas pada hari itu amat menentukan kelancaran posyandu. Dari pengalaman selama ini menunjukan bahwa kegiatan di posyandu bisa tertangani dengan baik bila jumlah kader 5 orang atau lebih. Bila kurang dari 5 orang, biasanya kader kewalahan melayani sasaran yang datang ke posyandu (Toriq, 2006).

Berdasarkan laporan Kabupaten/ Kota, jumlah puskesmas yang ada di Provinsi Lampung pada tahun 2011 sebanyak 275 dari 26 puskesmas perawatan dan 207 puskesmas non perawatan sedangkan jumlah posyandu di wilayah provinsi Lampung sebanyak 7.785 posyandu. Dari data Dinas Kesehatan Kabupaten Pringsewu jumlah posyandu yang ada di Kabupaten Pringsewu sebanyak 183 posyandu dan kader yang ada sebanyak 922 orang, selama tahun 2012 telah dilaporkan jumlah posyandu di wilayah kerja Puskesmas Wates yaitu sebanyak 23 posyandu yang ada. Untuk Desa Wates ada 2 posyandu dengan 10 kader, Desa Wates Timur 2 posyandu dengan 10 kader, Wates Selatan ada 2 posyandu dengan 10 kader, Bulokarto ada 3 posyandu dengan 16 kader, Bulurejo ada 3 posyandu dengan 14 kader, Panjirejo ada 3 posyandu dengan 13 kader, Blitarejo ada 3 posyandu dengan 15 kader, dan Desa Parerejo ada 5 posyandu dengan 27 kader. Didapatkan sekitar $40 \%$ kader masih ada yang kurang aktif dalam kegiatan pelaksanaan posyandu sehingga menimbulkan beberapa masalah, salah satunya kurangnya minat ibu untuk menimbang anaknya setiap bulan ke posyandu (Dinas Kesehatan Kabupaten Pringsewu, 2015).

Menurut data presurvey yang telah peneliti lakukan untuk wilayah Desa Parerejo, tercatat selama tahun 2015 jumlah posyandu yang ada sebanyak 5 posyandu yaitu posyandu Nusa Indah ada 6 orang kader, posyandu Sakura ada 6 orang kader, posyandu Melati ada 5 orang kader, posyandu Bugenvil ada 5 orang kader, dan posyandu Mawar ada 5 orang kader. Total jumlah kader ada 27 orang dalam 5 posyandu di Desa Parerejo. Dari jumlah yang ada didapatkan kader yang kurang aktif dalam kegiatan posyandu kurang lebih terdapat $10 \%$ kader dari jumlah yang tersedia. Dari data tersebut menunjukkan bahwa masih ada kader yang tidak aktif dalam setiap kegiatan posyandu yang dapat menimbulkan ketidak efektifan pelayanan posyandu.

\section{METODE PENELITIAN}

Penelitian ini menggunakan metode deskriptif analitik dengan pendekatan cross sectional. Alat ukur yang digunakan adalah kuesioner. Pada penelitian ini, penentuan 
sampel menggunakan teknik Cluster Sampling. Uji yang dilakukan menggunakan uji Chi Square. Teknik Cluster Sampling yang peneliti lakukan yaitu: dari 8 desa yang ada setelah dirandom, desa yang digunakan adalah Blitarejo, Wates Timur, Panjerejo, Bulukrejo dan didapatkan sampel yang digunakan sebanyak 52 responden. Kriteria sampel kader yang aktif yaitu melalui frekuensi kader mengikuti kegiatan posyandu yang diukur berdasarkan jumlah kehadirannya dalam melakukan kegiatan pada hari buka posyandu $\geq 8$ kali hadir dalam 12 bulan terakhir di wilayah kerja Puskesmas Wates Kecamatan Gadingrejo Kabupaten Pringsewu Lampung. Tingkat pengetahuan yaitu hal - hal yang diketahui, dimengerti dan mampu diingat oleh kader tentang program/kegiatan posyandu dan tugas kader posyandu dengan kategori baik, cukup dan kurang. Motivasi mengenai ada tidaknya dorongan yang timbul pada seorang kader dalam melaksanakan tugas pelayanan kesehatan dasar. Penelitian ini dilaksanakan di wilayah kerja Puskesmas Wates Kecamatan Gadingrejo Kabupaten Pringsewu Lampung pada bulan Mei-Agustus 2016.

\section{HASIL}

\section{HASIL PENELITIAN}

\section{A. Univariat}

1. Keaktifan Kader Posyandu

Tabel 1 Distribusi

Frekuensi

Responden Berdasarkan

Keaktifan Kader Posyandu

\begin{tabular}{ccc}
\hline $\begin{array}{c}\text { Keaktifan } \\
\text { kader } \\
\text { posyandu }\end{array}$ & Frekuensi & $\begin{array}{c}\text { Presentase } \\
\text { (\%) }\end{array}$ \\
\hline $\begin{array}{c}\text { Aktif } \\
\text { Kurang } \\
\text { Aktif }\end{array}$ & 32 & $61,5 \%$ \\
\hline Total & 20 & $38,5 \%$ \\
\hline \multicolumn{3}{c}{ Berdasarkan tabel di atas, }
\end{tabular}

dapat disimpulkan bahwa kader yang aktif dalam kegiatan posyandu sebagian besar ibu aktif dalam kegiatan posyandu sebanyak 32 responden $(61,5 \%)$.

2. Pengetahuan

Tabel 2 Distribusi

Frekuensi

Responden Berdasarkan Tingkat Pengetahuan Kader Posyandu

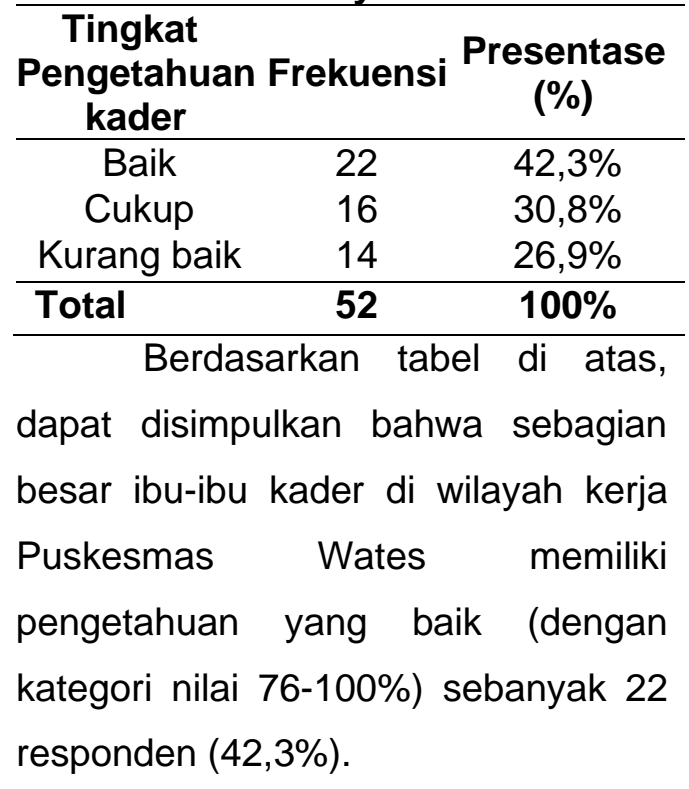

3. Motivasi

Tabel 3 Distribusi Frekuensi Responden Berdasarkan Motivasi Kader Posyandu

\begin{tabular}{ccc}
\hline Motivasi & Frekuensi & $\begin{array}{c}\text { Presentase } \\
(\%)\end{array}$ \\
\hline Ada & 33 & $63,5 \%$ \\
Tidak Ada & 19 & $36,5 \%$ \\
\hline Total & $\mathbf{5 2}$ & $\mathbf{1 0 0 \%}$
\end{tabular}


Berdasarkan tabel di atas, dapat disimpulkan bahwa sebagian besar ibu-ibu kader di wilayah kerja Puskesmas Wates memperoleh motivasi sebanyak 33 responden (63,5\%).

\section{B. Bivariat}

1. Tingkat Pengetahuan Dengan Keaktifan Kader Posyandu

Tabel 4 Korelasi Tingkat Pengetahuan Dengan Keaktifan Kader Posyandu

\begin{tabular}{|c|c|c|c|c|c|c|}
\hline \multirow{3}{*}{$\begin{array}{l}\text { Tingkat } \\
\text { Pengetahu } \\
\text { an }\end{array}$} & \multicolumn{4}{|c|}{$\begin{array}{c}\text { Keaktifan kader } \\
\text { posyandu }\end{array}$} & \multicolumn{2}{|c|}{ Total } \\
\hline & \multicolumn{2}{|c|}{ Aktif } & \multicolumn{2}{|c|}{$\begin{array}{c}\text { Kurang } \\
\text { Aktif }\end{array}$} & \multirow[t]{2}{*}{$\mathbf{N}$} & \multirow[t]{2}{*}{$\%$} \\
\hline & $\mathbf{N}$ & $\%$ & $\mathbf{N}$ & $\%$ & & \\
\hline Baik & 20 & $909 \%$ & 2 & $9,1 \%$ & 22 & $100 \%$ \\
\hline Cuku & 10 & $62,5 \%$ & 6 & $37,5 \%$ & 16 & $100^{\circ}$ \\
\hline $\begin{array}{l}\text { Kurang } \\
\text { Baik }\end{array}$ & 2 & $14,3 \%$ & 12 & $85,7 \%$ & 14 & $100 \%$ \\
\hline Jumlah & 32 & $61,5 \%$ & 20 & $38,5 \%$ & 52 & $100 \%$ \\
\hline
\end{tabular}

Berdasarkan tabel 4 dari 22 responden dengan tingkat pengetahuan baik yang aktif dalam kegiatan posyandu sebanyak 20 responden $(90,9 \%)$ dan dari tingkat pengetahuan baik yang kurang aktif dalam kegiatan posyandu sebanyak 2 responden (9,1\%). Hasil analisis untuk korelasi tingkat pendidikan dengan keaktifan kader posyandu melalui uji chi square didapatkan nilai $p$ value adalah 0,000 atau $<0,05$ ini berarti menyatakan bahwa ada korelasi yang signifikan antara tingkat pengetahuan dengan keaktifan kader posyandu.
2. Motivasi Dengan Keaktifan Kader Posyandu

Tabel 5 Korelasi Motivasi Dengan Keaktifan Kader Posyandu Keaktifan kader posyandu Total

\begin{tabular}{|c|c|c|c|c|c|c|}
\hline \multirow{3}{*}{ Motivasi } & \multicolumn{4}{|c|}{$\begin{array}{c}\text { Keaktifan kader } \\
\text { posyandu }\end{array}$} & \multicolumn{2}{|c|}{ Total } \\
\hline & \multicolumn{2}{|r|}{ Aktif } & \multicolumn{2}{|c|}{$\begin{array}{c}\text { Kurang } \\
\text { Aktif }\end{array}$} & \multirow[t]{2}{*}{$\mathbf{N}$} & \multirow[t]{2}{*}{$\%$} \\
\hline & $\mathbf{N}$ & $\%$ & $\mathbf{N}$ & $\%$ & & \\
\hline Ada & 25 & $75,8 \%$ & 8 & $24,2 \%$ & 33 & $100 \%$ \\
\hline $\begin{array}{l}\text { Tidak } \\
\text { Ada }\end{array}$ & 7 & $36,8 \%$ & 12 & $63,2 \%$ & 19 & $100 \%$ \\
\hline Total & 32 & $61,5 \%$ & 20 & $38,5 \%$ & 52 & $100 \%$ \\
\hline
\end{tabular}
responden dengan kader yang mendapatkan motivasi yang aktif dalam kegiatan posyandu sebanyak 25 responden $(75,8 \%)$ dan dari kader yang tidak mendapat motivasi yang kurang aktif dalam kegiatan posyandu sebanyak 12 responden (63,2\%). Hasil analisis korelasi tingkat pendidikan dengan keaktifan kader posyandu melalui uji chi square didapatkan nilai $p$ value adalah 0,013 atau $<0,05$ ini berarti menyatakan bahwa ada korelasi antara motivasi dengan keaktifan kader posyandu.

\section{PEMBAHASAN}

\section{A. Univariat}

\section{Keaktifan Kader Posyandu}

Hasil penelitaian menyatakan hasil bahwa ibu kader yang aktif dalam posyandu sebanyak 32 responden $(61,5 \%)$ dan yang kurang aktif dalam kegiatan posyandu sebanyak 20 responden (38,5\%). Berdasarkan hasil tersebut dapat 
diketahui bahwa jumlah kader yang aktif lebih banyak dibanding yang tidak aktif, tetapi jika dilihat kembali dan dihitung berdasarkan jumlah posyandu maka keaktifan kader masih kurang, hal tersebut dapat diketahui dengan jumlah rata-rata kehadiran kader posyandu yang aktif (hadir $\geq 8$ kali/tahun) masih kurang dari 6 kader di setiap posyandu yang ada. Kader yang aktif adalah kader yang selalu datang ke kegiatan posyandu, dan posyandu yang baik adalah posyandu yang diselenggarakan $\quad \geq 8 \quad$ kali/tahun (Departemen Kesehatan RI, 2011).

Kader posyandu yang tidak aktif dalam kegiatan posyandu akan berdampak pada keluarga yang kurang memanfaatkan pelayanan kesehatan seperti posyandu sehingga dapat mengalami kurangnya informasi tentang kesehatan (Achjar Henny A.K, 2010).

\section{Pengetahuan}

Berdasarkan hasil penelitian mengenai pengetahuan, sebagian besar ibu-ibu kader di wilayah kerja Puskesmas Wates memiliki pengetahuan yang baik (dengan kategori nilai $76-100 \%$ sebanyak 22 responden (42,3\%).

Kader diharapkan memiliki tingkat pengetahuan yang baik mengenai tujuan dan manfaat posyandu sehingga sikap kader tersebut akan mendukung motivasi yang tinggi untuk aktif dalam kegiatan posyandu (Sistiriani, et al., 2013)/ Maka dengan demikian pengetahuan merupakan tahap awal seseorang berbuat sesuatu dan pengetahuan tentang apa yang akan dilakukan membuat seseorang mengetahui langkah selanjutnya yang harus diperbuat. Seorang kader posyandu harus mengetahui tentang tugas yang diembannya sehingga dapat memberikan pelayanan maksimal kepada masyarakat dalam mengelola posyandu. (Suhat \& Hasanah 2014).

\section{Motivasi}

Berdasarkan hasil penelitian didapatkan hasil bahwa ibu kader yang mendapatkan motivasi sebanyak 33 responden (63,5\%) dan yang tidak mendapatkan motivasi sebanyak 19 responden (36,5\%).

Menurut Hamzah (2012) motivasi adalah dorongan dasar yang menggerakan seseorang bertingkah laku. Motivasi juga dapat dikatakan sebagai perbedakaan antara dapat melaksanakan atau mau melaksanakan atau motivasi juga dapat diartikan sebagai proses untuk mencoba mempengaruhi orang atau orang-orang yang dipimpinnya agar melakukan pekerjaan yang diinginkan. 


\section{B. Bivariat}

1. Korelasi Pengetahuan dengan Keaktifan Kader

Berdasarkan hasil analisis keaktifan kader posyandu melalui uji chi square didapatkan nilai $p$ value adalah 0,007 atau $<0,05$ ini berarti menyatakan bahwa ada korelasi antara pengetahuan dengan keaktifan kader posyandu.

Hal itu sesuai dengan penelitian Dodo (2008), didapatkan hubungan yang bermakna antara pengetahuan dengan tingkat keaktifan kader posyandu di wilayah kerja Puskesmas Sikumana. Tingginya tingkat pengetahuan kader menjadikan kinerja kader baik dan berdampak terhadap pelaksanaan program posyandu tersebut. Semakin baik atau semakin tinggi pengetahuan kader, semakin tinggi atau semakin baik pula tingkat keaktifannya dalam proses pelaksanaan kegiatan posyandu.

Penelitian lain juga mengungkapkan bahwa terdapat hubungan yang erat antara pengetahuan dengan keaktifan kader dalam kegiatan posyandu dikarenakan pengetahuan merupakan tahap awal seseorang berbuat sesuatu dan pengetahuan tentang apa yang akan dilakukan membuat seseorang mengetahui langkah selanjutnya yang harus diperbuat. Hal ini sesuai dengan penelitian yang dilakukan oleh Suhat \& Hasanah (2014) yang menyatakan bahwa ada hubungan antara pengetahuan dengan keaktifan kader kesehatan.

Kader diharapkan dapat
menjembatani antara petugas
kesehatan dengan masyarakat serta membantu masyarakat mengidentifikasi dan menjawab kebutuhan kesehatan mereka sendiri. Kader juga diharapkan dapat menyediakan informasi bagi pemangku kebijakan kesehatan wilayah setempat yang mungkin tidak dapat mencapai masyarakat langsung, serta mampu mendorong agar sistem kesehatan dapat mengerti dan merespons kebutuhan masyarakat. (Mubarak dan Chayatin N, 2009).

\section{Korelasi Motivasi dengan} Keaktifan Kader

Berdasarkan hasil analisis, motivasi sangat berpengaruh terhadap keaktifan kader posyandu karena terbukti bahwa kader yang mendapatkan dukungan atau motivasi lebih semangat bekerja karena merasa dihargai, dianggap ada dan merasa lebih percaya diri. Maka demikian dari berbagai macam defenisi motivasi ada tiga poin penting dalam pengertian motivasi 
yaitu hubungan antara kebutuhan, dorongan dan tujuan. Kebutuhan muncul karena adanya semangat yang kurang dirasakan oleh seseorang baik fisiologis maupun psikologis.

Maka keaktifan posyandu dipengaruhi oleh banyak faktor. Salah satu dari faktor-faktor tersebut terbagi menjadi faktor dari dalam maupun dari luar posyandu. Faktor dari dalam posyandu berupa kader, dana dan sarana prasarana. Sedangkan faktor dari luar posyandu berupa tingkat pendidikan dan sosial ekonomi masyarakat serta jumlah balita. Berdasarkan hasil diskusi diperoleh bahwa sebagian besar kader yang aktif memiliki motivasi berupa kebutuhan agar dapat memahami informasi tentang pelayanan kesehatan terkini dan tujuan bahwa kader merasa bahagia dan bangga dengan tugas yang dijalankan karena mereka telah dianggap sebagai bagian dari dinas kesehatan dan sebagai wadah silahturahmi serta memperoleh kolega.

\section{KESIMPULAN}

Dari hasil penelitian ini didapatkan kesimpulan sebagian besar memiliki pengetahuan yang baik sebanyak 22 responden $(42,3 \%)$, sebagian besar ibu-ibu kader diwilayah kerja Puskesmas Wates memperoleh motivasi sebanyak 33 responden (63,5\%), sebagian besar ibu aktif dalam kegiatan posyandu sebanyak 32 responden (61,5\%). Ada hubungan yang signifikan antara tingkat pengetahuan dengan keaktifan kader posyandu di wilayah kerja Puskesmas Wates tahun 2016 dengan $p$ $<0,05$ yaitu $p$ Value 0,000 dan ada hubungan yang signifikan antara motivasi dengan keaktifan kader posyandu di wilayah kerja Puskesmas Wates tahun 2016 dengan $p$ $<0,05$ yaitu $p$ Value 0,013

Untuk itu upaya peningkatan pengetahuan dan kesejahteraan kader perlu diperhatikan lagi guna peningkatan peran aktif kader posyandu.

\section{DAFTAR PUSTAKA}

Achjar, Komang Ayu Henny. 2010. Aplikasi Praktis Asuhan Keperawatan Keluarga Cetakan I. Jakarta: Sagung Seto

Departemen Kesehatan RI. 2006. Pedoman Umum Pengelolaan Posyandu. Jakarta: Departemen Kesehatan RI.

Depkes RI. 2011. Pedoman Umum Pengelolaan Posyandu. Jakarta: Departemen Kesehatan RI

Dinas Kesehatan Kabupaten Pringsewu, tahun 2015

Dodo, D. 2009. Faktor - Faktor yang Berhubungan dengan Keaktifan Kader dalam Pelaksanaan Kegiatan Posyandu di Kelurahan. Jurnal Pangan, Gizi dan Kesehatan Tahun 1, vol 1, no 1 April.

Meilani, N; Setiyawati, N; Estiwidani, D; dkk. 2010. Pelayanan keluarga berencana. Jogjakarta: Fitramaya.

Mubarak dan Chayatin N. 2009. IImu kesehatan masyarakat, teori dan aplikasi. Jakarta: Salemba Medika. 
Toriq. 2006. Peranan Kader Pos Pelayanan Terpadu (Posyandu) dalam pembangunan kesehehatan masyarakat (studi kasus di Kelurahan Sekaran Kecamatan Gunungpati Kota Semarang). Semarang: Jurusan Pendidikan Luar Sekolah, Fakultas IImu Pendidikan, UNES

Sistiarani, C., Nurhayati, S. and -, S. 2013 'PERAN KADER DALAM PENGGUNAAN BUKU KESEHATAN IBU DAN ANAK', Jurnal Kesehatan Masyarakat, 8(2), pp. 99-105. doi: ISSN 1858-1196

Suhat dan Hasanah R. 2014. Faktor-faktor Yang Berhubungan dengan Keaktifan Kader Dalam Kegiatan Posyandu (Studi di Puskesmas Palasari Kabupaten Subang). Jurnal Kesehatan Masyarakat. Kemas.Vol. 10. No. 1 